University of Wollongong

Research Online

Faculty of Science, Medicine and Health -

Papers: Part B

Faculty of Science, Medicine and Health

$1-1-2020$

\title{
Climate Change Significantly Alters Future Wildfire Mitigation Opportunities in Southeastern Australia
}

\author{
Giovanni Di Virgilio \\ Jason P. Evans \\ Hamish Clarke \\ University of Wollongong, hamishc@uow.edu.au \\ Jason J. Sharples \\ Annette Hirsch
}

See next page for additional authors

Follow this and additional works at: https://ro.uow.edu.au/smhpapers1

\section{Publication Details Citation}

Di Virgilio, G., Evans, J. P., Clarke, H., Sharples, J. J., Hirsch, A., \& Hart, M. (2020). Climate Change Significantly Alters Future Wildfire Mitigation Opportunities in Southeastern Australia. Faculty of Science, Medicine and Health - Papers: Part B. Retrieved from https://ro.uow.edu.au/smhpapers1/1513 


\title{
Climate Change Significantly Alters Future Wildfire Mitigation Opportunities in Southeastern Australia
}

\author{
Abstract \\ (C2020. American Geophysical Union. All Rights Reserved. Prescribed burning is used globally to mitigate \\ the risks of wildfires, with severe wildfires increasing in frequency in recent decades. Despite their \\ importance in wildfire management, the nature of future changes to prescribed burn windows under \\ global warming remains uncertain. We use a regional climate projection ensemble to provide a robust \\ spatiotemporal quantification of statistically significant future changes in prescribed burn windows for \\ southeastern Australia. There are significant decreases during months presently used for prescribed \\ burning, that is, in March to May in 2060-2079 versus 1990-2009 across several temperate regions. \\ Conversely, burn windows show widespread significant increases in June to August, that is, months when \\ burns have rarely occurred historically, and also in spring (September-October). Overall, projected \\ changes in temperature and fuel moisture show the most widespread and largest decreases (or \\ increases) in the number of days within their respective ranges suitable for conducting burns. These \\ results support wildfire risk mitigation planning.

\section{Publication Details} \\ Di Virgilio, G., Evans, J., Clarke, H., Sharples, J., Hirsch, A. \& Hart, M. (2020). Climate Change Significantly \\ Alters Future Wildfire Mitigation Opportunities in Southeastern Australia. Geophysical Research Letters, \\ 47 (15), e2020GL088893.
}

\section{Authors}

Giovanni Di Virgilio, Jason P. Evans, Hamish Clarke, Jason J. Sharples, Annette Hirsch, and Melissa Hart 


\section{Geophysical Research Letters}

\author{
RESEARCH LETTER \\ 10.1029/2020GL088893 \\ Key Points: \\ - Significant decreases in wildfire \\ mitigation windows occur in \\ March-May in 2060-2079 versus \\ 1990-2009 but increase in \\ June-August in 2060-2079 \\ - Projected temperature and fuel \\ moisture changes have the largest \\ contribution to the change in the \\ wildfire mitigation window \\ - Locations in southeast Australia \\ where changes in wildfire mitigation \\ windows are projected to occur are \\ identified on a monthly basis
}

Supporting Information:

- Supporting Information S1

Correspondence to:

G. Di Virgilio,

giovanni@unsw.edu.au

Citation:

Di Virgilio, G., Evans, J. P., Clarke, H., Sharples, J., Hirsch, A. L., \& Hart, M. A. (2020). Climate change significantly alters future wildfire mitigation opportunities in southeastern Australia. Geophysical Research Letters, 47, e2020GL088893. https://doi.org/ 10.1029/2020GL088893

Received 20 MAY 2020 Accepted 23 JUN 2020 Accepted article online 8 JUL 2020

(c)2020. American Geophysical Union. All Rights Reserved.

\section{Climate Change Significantly Alters Future Wildfire Mitigation Opportunities in Southeastern Australia}

\author{
Giovanni Di Virgilio $^{1}$ (D) Jason P. Evans ${ }^{1,2}$ (D), Hamish Clarke ${ }^{3,4,5}$ (D) Jason Sharples ${ }^{6,7}$, \\ Annette L. Hirsch ${ }^{1,2}$ (D) and Melissa Anne Hart ${ }^{1,2}$ (D) \\ ${ }^{1}$ Climate Change Research Centre, University of New South Wales, Sydney, NSW, Australia, ${ }^{2}$ Australian Research \\ Council Centre of Excellence for Climate Extremes, University of New South Wales, Sydney, NSW, Australia, ${ }^{3}$ Centre for \\ Environmental Risk Management of Bushfires, University of Wollongong, Wollongong, NSW, Australia, ${ }^{4}$ Hawkesbury \\ Institute for the Environment, Western Sydney University, Penrith, NSW, Australia, ${ }^{5}$ NSW Bushfire Risk Management \\ Research Hub, Wollongong, NSW, Australia, ${ }^{6}$ School of Science, University of New South Wales, Canberra, ACT, \\ Australia, ${ }^{7}$ Bushfire and Natural Hazards Cooperative Research Centre, University of New South Wales, East Melbourne, \\ Victoria, Australia
}

Abstract Prescribed burning is used globally to mitigate the risks of wildfires, with severe wildfires increasing in frequency in recent decades. Despite their importance in wildfire management, the nature of future changes to prescribed burn windows under global warming remains uncertain. We use a regional climate projection ensemble to provide a robust spatiotemporal quantification of statistically significant future changes in prescribed burn windows for southeastern Australia. There are significant decreases during months presently used for prescribed burning, that is, in March to May in 2060-2079 versus 1990-2009 across several temperate regions. Conversely, burn windows show widespread significant increases in June to August, that is, months when burns have rarely occurred historically, and also in spring (September-October). Overall, projected changes in temperature and fuel moisture show the most widespread and largest decreases (or increases) in the number of days within their respective ranges suitable for conducting burns. These results support wildfire risk mitigation planning.

Plain Language Summary The frequency of destructive wildfires is increasing in many fire-prone regions, threatening lives, property, and damaging the environment. To reduce the risk of wildfires occurring, agencies conduct planned, controlled, and preemptive burns of vegetation to reduce the available fuel load. Currently, in southeastern Australia, these "prescribed burns" are conducted during autumn (March-May) and early spring (September) but rarely during winter (June-August). Given climate change, we need to understand how opportunities for conducting these burns might change in future. This is particularly important for forest and woodland areas adjacent to populated urban areas. We use regional climate projection data to assess future changes to the suitability for prescribed burning. We demonstrate that over many regions, windows are projected to decrease during months currently used for conducting burns in 2060-2079 compared to 1990-2009. In contrast, they generally increase in the winter months and further into spring (September-October). This change in seasonality means that these periods could be more suitable for conducting burns in future. Future changes in burn windows are most strongly associated with changes in temperature and vegetation moisture content, though there are many other contributing factors to these changes. These findings are relevant to strategic wildfire prevention and regional risk mitigation.

\section{Introduction}

Australia is one of several regions to frequently experience severe wildfires, most recently the devastating fires that occurred during 2019-2020, the costs of which could exceed \$4.4 billion (Ell, 2020). Prescribed burns are preemptive, targeted, and controlled burns performed in Australia and internationally to reduce the risk of wildfires (Moritz et al., 2014). In this context, their aim is to achieve a controlled reduction of the fuel load in order to reduce wildfire severity or likelihood of occurrence (Fernandes \& Botelho, 2003). Globally, prescribed burns are also used for forest management, agriculture, ecosystem restoration, and in some locations, greenhouse gas abatement (Ansell et al., 2020). Fire regimes vary in Australia, ranging from high frequencies but low intensities in the northern semitropical savannas, to relatively lower frequencies 


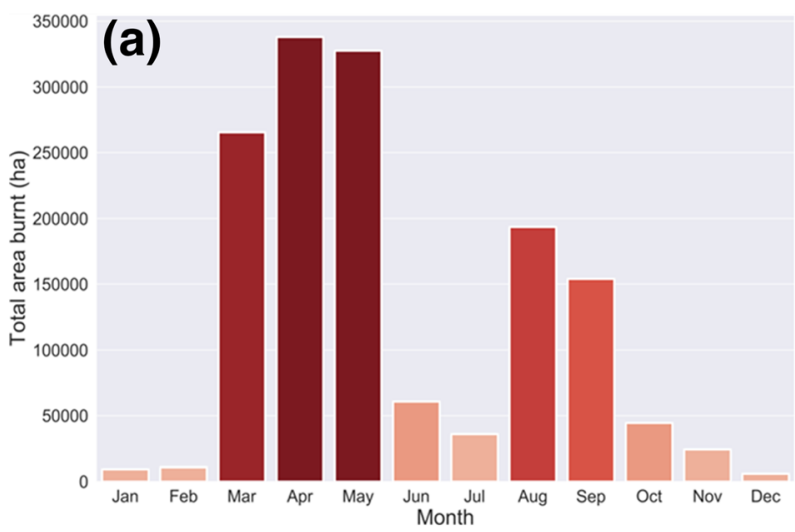

\begin{tabular}{lcc}
\hline (b) $\quad$ Variable & & Observed \\
\hline Maximum temperature $\left({ }^{\circ} \mathrm{C}\right)$ & Min & 16.5 \\
& Max & 28.5 \\
Relative humidity $(\%)$ & Min & 30.7 \\
& Max & 56.4 \\
Wind speed $(\mathrm{km} / \mathrm{h})$ & Max & 24.1 \\
Wind speed 3 day outlook $(\mathrm{km} / \mathrm{h})$ & Max & 27.7 \\
Forest Fire Danger Index $(\mathrm{FFDI})$ & Min & 1.9 \\
& Max & 12.9 \\
FFDI 3 day outlook & Max & 15.2 \\
Fuel moisture $(\%)$ & Min & 9.1 \\
& Max & 17.1 \\
\hline
\end{tabular}

Figure 1. (a) Total area burnt (hectares [ha]) by prescribed burns each month during 2004-2016 in New South Wales (NSW), southeastern Australia. Source: NSW Rural Fire Service (2016). (b) Weather definitions used to assess whether conditions are suitable for prescribed burning in sclerophyll communities. These definitions are based on actual weather observed during recorded prescribed burns. See Clarke et al. (2019) for further details of how definitions were derived.

but higher intensities in the temperate southeast considered here (Bradstock, 2010). In southeastern Australia, prescribed burns are typically conducted during the cooler "shoulder season" months, that is, throughout autumn (March, April, May), late winter (August), and early spring (September) (Figure 1a). Several factors are considered when planning prescribed burns, including vegetation type, topography, proximity to property, desired fire intensity, rate of spread and extent, and operational constraints such as smoke dispersal over populated areas (Di Virgilio et al., 2018; Office of Environment and Heritage, 2019). Fire agencies also assess a range of weather conditions in order to determine whether prescribed burns can occur at a given time and location (Figure 1b). It is important that burns are conducted during weather conditions that are suitable for controllable burns that present minimal risk to the public and property, while also achieving mitigation aims.

Internationally, the frequency and duration of wildfires are predicted to increase by the end of the century (Flannigan et al., 2013). Climate change is already driving wildfire weather conditions away from the expected range of internal variability for a large portion of the globe, and this will become more widespread with continued global warming (Abatzoglou et al., 2019). Wildfire frequencies have increased in North America since the 1980s (Westerling, 2016), and increases in the frequency of severe wildfires are expected in Australia with climate change (Di Virgilio et al., 2019; Dowdy et al., 2019). Moreover, urbanization into wildfire-prone regions increases exposure to the risks associated with wildfires (Knorr et al., 2016). Consequently, land management and fire agencies are under pressure to reduce exposure to wildfire hazards. Prescribed burning may therefore be used more extensively, both as a response to the increasing probability of fire risk (Krofcheck et al., 2018; Tarancon et al., 2014) and as a mandated risk mitigation measure (Teague et al., 2010). However, despite the importance of prescribed burning in wildfire management, a greater understanding of how prescribed burn weather conditions may change under global warming is required. Previous studies have indicated varying prognoses for prescribed burn windows. For instance, Prichard et al. (2017) suggest that the prescribed burn window may decrease across various regions, while Williamson et al. (2016) and Ximenes et al. (2017) suggest that it is already decreasing. These changes are generally attributed to factors driven by climate change, such as rising temperatures and altered precipitation patterns (Mitchell et al., 2014). However, many of these studies were qualitative in nature.

Clarke et al. (2019) conducted the first quantitative assessment of future changes in prescribed burn windows using weather definitions for coastal New South Wales (NSW) in southeastern Australia. Focusing on annual changes in prescribed burning days, they found weak evidence for a decrease in burn days under projected climate change, instead finding the potential for widespread increases in current burning seasons. However, given the strong monthly variation in prescribed burning, there is a clear requirement for a spatiotemporal quantification of future monthly changes to burn windows in a changing climate and an assessment of the statistical significance of these changes. Moreover, a quantification of how future changes to individual fire weather variables contribute to changes in burn windows has not previously been 
performed. Therefore, we use a regional climate projection ensemble to examine projected changes to burn windows across southeastern Australia, providing the first robust analyses of where and when changes are statistically significant on a monthly basis. We then determine the significant changes to the key weather variables that potentially drive shifts in future prescribed burn windows.

\section{Materials and Methods}

\subsection{Prescribed Burns Historical Data}

To obtain an overview of the monthly variation of prescribed burning in the current period using the state of NSW as an example (Figure 1a), historical records of prescribed burns were obtained from the NSW Rural Fire Service (2016), the agency responsible for prescribed burning in this region. Prescribed burns lacking a start or end-date (3\%) were omitted, leaving 8,607 burn records conducted during January 2004 to December 2016. The overall area burnt in late winter/early spring is lower than during autumn, due to a higher number of individual spring burns that are smaller in area.

\subsection{Climate Projections}

An ensemble of 12 regional climate model (RCM) simulations over southeastern Australia was used to generate climate change projections. The simulations covered two 20-year periods: historical (1990-2009) and far-future (2060-2079). Far-future projections followed the A2 (high emissions) scenario from the Special Report on Emissions Scenarios (Nakićenović et al., 2000). These simulations are part of the NSW/Australian Capital Territory Regional Climate Modelling (NARCliM) project to produce climate projections for southeastern Australia. The NARCliM ensemble has been comprehensively evaluated (Bao et al., 2017; Cortes-Hernandez et al., 2016; Fita et al., 2017), including for the simulation of surface fire weather conditions (Clarke \& Evans, 2019; Di Virgilio et al., 2019), where these were approximated by the McArthur Forest Fire Danger Index (FFDI; Noble et al., 1980). These RCMs also confer added value to their driving global climate models (GCMs) (Di Luca et al., 2016).

This ensemble was created by selecting four GCMs (MIROC3.2-medres, ECHAM5, CCCMA3.1, and CSIROMk3.0) from the third Coupled Model Intercomparison Project (CMIP3) based on their skill in simulating the Australian climate and model independence. Although CMIP5 downscaled projections are now available over some domains, we note that, for both large-scale climate patterns and the magnitudes of climate change, there is overall consistency between CMIP3 and CMIP5 projections (Collins et al., 2014). GCM outputs were dynamically downscaled using three configurations of the Weather Research and Forecasting (WRF) model version 3.3 (Skamarock et al., 2008). Each configuration used different parameterizations for surface/planetary boundary layer, cumulus convection, and atmospheric radiation but used the same dynamical core, land surface model, and subgrid-scale microphysics scheme (Evans et al., 2014). The three configurations were selected from a 36-member ensemble that used different physical parameterizations based on their model skill and independence (Evans et al., 2012; Ji et al., 2014). RCM simulations were conducted using a nested approach with an outer domain covering the CORDEX-Australasia region with a resolution of $\sim 50 \mathrm{~km}$. The initial and lateral boundary conditions from the outer grid simulation were then used to drive the same RCM over an inner domain covering southeastern Australia at approximately 10-km resolution. Analyses focus on the inner domain. Daily total precipitation, daily maximum temperature, daily $3 \mathrm{p}$. m. relative humidity, and daily 3 p.m. wind speed were standard outputs for each RCM. Temperature and humidity were used to estimate daily fine dead fuel moisture (FM) following de Dios et al. (2015) and Nolan et al. (2016). FFDI was calculated following Finkele et al. (2006) using near-surface daily maximum temperature, wind speed and relative humidity, and the daily drought factor (Noble et al., 1980).

\subsection{Prescribed Burn Day Definition}

Burn days were designated as days when all weather conditions matched the observed weather definitions (Figure 1b). Additionally, we identified days when individual weather variables matched their respective definitions. These are the same definitions that Clarke et al. (2019) based on actual weather observed during recorded prescribed burns in dry sclerophyll forests in temperate and subtropical NSW. Most regions of Australia that support woody plants are occupied by sclerophyll communities as forests, heaths, or savannas (Tozer et al., 2017), and these communities are highly fire prone (Bradstock et al., 1997; Penman et al., 2007). We therefore consider that these same criteria will be broadly applicable across the temperate and 
subtropical regions of southeastern Australia, noting that the different government jurisdictions and agencies operating across this domain may apply slightly different burn criteria.

\subsection{Future Changes to Burn Windows}

Future changes in the ensemble mean number of days per month that are within the thresholds for conducting burns were calculated by subtracting the ensemble mean monthly averages for 2060-2079 (far-future) from those of 1990-2009 (present-day). Ensemble mean climate change signals for the individual fire weather variables were calculated as far future minus present-day. The statistical significance of projected changes in the monthly mean number of burn days relative to 1990-2009 was calculated for each grid cell using $t$ tests $(\alpha=0.05)$ assuming equal variance. Results on ensemble mean statistical significance were separated into three classes following Tebaldi et al. (2011). Statistically insignificant areas are shown in color. These are locations where fewer than $50 \%$ of the models are significantly different from the corresponding number of burn days for 1990-2009. In areas of significant agreement (stippled), at least 50\% of RCMs show that the number of mean burn days in 2060-2079 is significantly different from 1990-2009, and at least 75\% of significant RCMs agree on the direction of change. Areas of significant disagreement are grid cells where at least $50 \%$ of RCMs are significantly different and fewer than $75 \%$ of significant models agree on change direction. These areas are mapped in color and superimposed with diagonal hashing. Additionally, areas where there are no burn days in either period are masked in gray.

\section{Results}

\subsection{Future Changes in Prescribed Burn Windows}

The months during which most prescribed burns currently occur (March-May) show statistically significant projected reductions in the mean number of days for conducting burns in many regions in 2060-2079, relative to 1990-2009 (Figures 2c-2e). Such regions include the heavily populated east coast of NSW in March and April, and much of southeastern Queensland (QLD) in April and May. Parts of coastal South Australia (SA) also show significant reductions during March. In most of these locations, mean burn days reduce by approximately 1-1.5 days per month. In many cases, this amounts to a reduction of $\sim 50 \%$ (Figures S1c-S1e in the supporting information). However, several other regions also show increases in burn windows, that is, over much of Victoria (VIC) during April, and more broadly over southern regions in May (Figures $2 \mathrm{~d}$ and 2e). In general, the semiarid, inland regions of southeastern Australia where sclerophyll communities are not found (i.e., central and northwestern areas) either show statistically insignificant changes, significant disagreeing areas, or are masked.

There are statistically significant projected increases in the mean number of days for conducting burns over large regions of southeastern Australia during winter, that is, during June to August, relative to the historical period (Figures $2 \mathrm{f}-2 \mathrm{~h}$ ). These significant increases include large portions of coastal NSW during these months and over southeastern QLD during June and July. Burn windows increase by approximately 1-2 days on average during these months over these regions, amounting to increases from 50\% to over $100 \%$ (Figures S1f-S1h). In contrast, changes over most of VIC are minimal during these months. However, there are also significant increases over several regions including VIC during September and October (Figures $2 \mathrm{i}$ and $2 \mathrm{j}$ ). A consistent exception to this general pattern of increases to burn windows from June to October is a marked reduction in burn days along the northeastern QLD coast (Figures 2f-2j).

\subsection{Future Changes in Burn Windows: Individual Variables}

Here, we examine projected changes in monthly prescribed burning days and climate change signals for individual variables. We focus on May and June because despite being adjacent months, May is currently a key month for conducting prescribed burns, whereas burns are rarely conducted during June (Figure 1a). It is likely that fewer burns are currently conducted in June due to generally wetter and cooler conditions, as well as increased strength of inversions increasing the chances of lingering fine particulate emissions from fires. However, both months showed strong projected changes to their burn windows.

During May in 2060-2079, there is a statistically significant increase of over 4.5 days on average when projected maximum temperature is within its thresholds for conducting burns over most of the temperate zone in southeastern Australia (Figure 3a). In contrast, projected changes to maximum temperature windows over the northeastern portion of the domain show large areas of statistically significant disagreement 

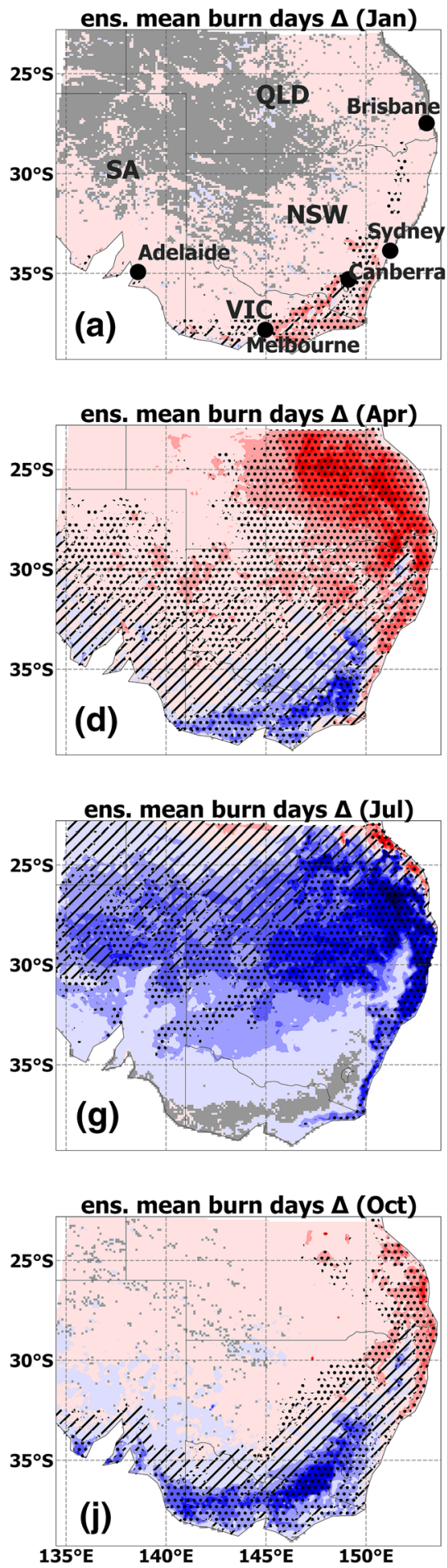

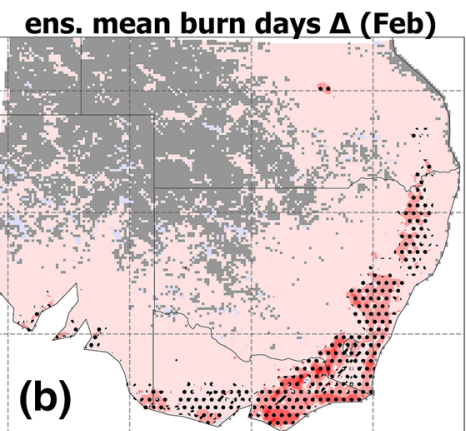

ens. mean burn days $\Delta$ (May)
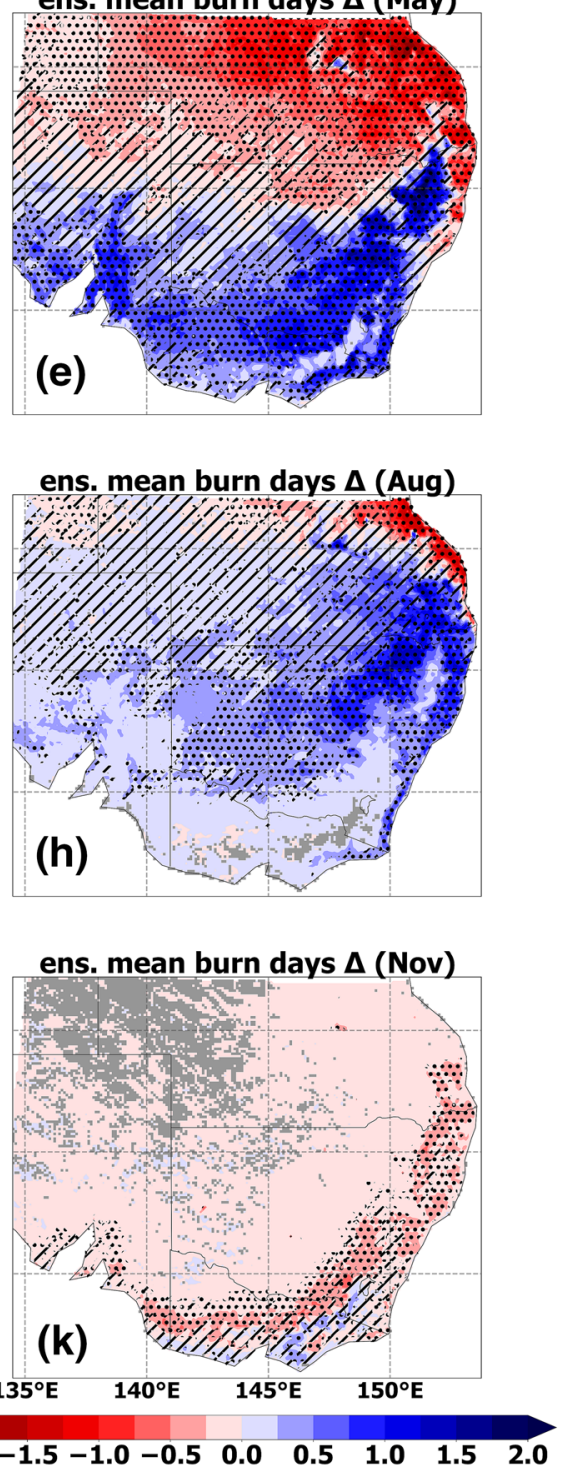
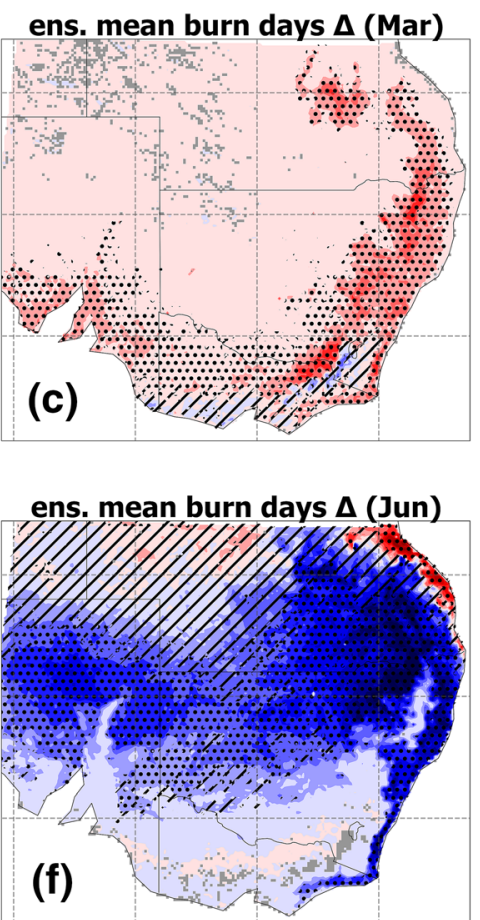

ens. mean burn days $\Delta$ (Sep)
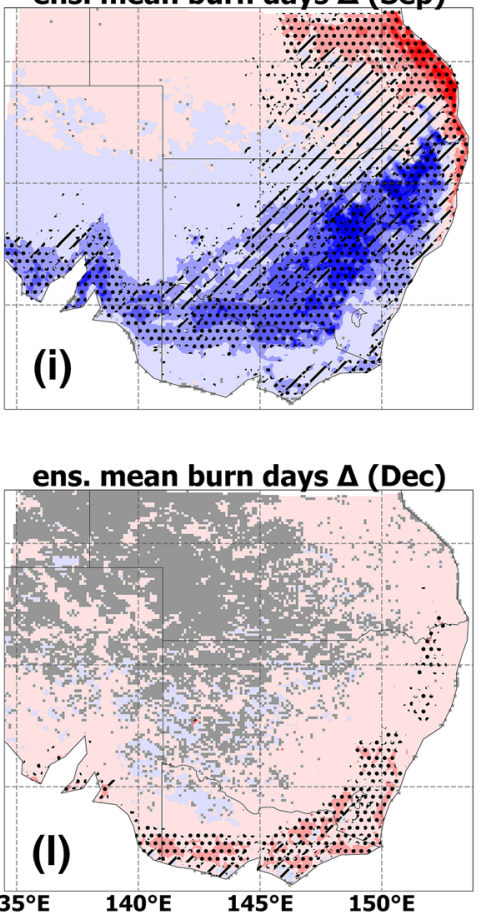

Change in $\mu$ no. days within observed thresholds for conducting burns, 2060-79 minus 1990-09

Figure 2. (a-1) Changes in the ensemble mean number of days within thresholds for conducting burns in 2060-2079 versus 1990-2009. (a) QLD = Queensland; NSW = New South Wales; VIC = Victoria; SA = South Australia. Significance stippling (a-1): statistically insignificant areas shown in color, $(<50 \%$ of the models are significantly different from burn days during 1990-2009). In significant agreeing areas (stippled using dots), at least 50\% of RCMs are significantly different to 1990-2009, and at least $75 \%$ of significant RCMs agree on the change direction. Significant disagreeing areas (at least 50\% of RCMs are significantly different, and $<75 \%$ significant models agree on change direction) shown in color with diagonal lines. Areas where there are no burn days in either period are masked (gray). 

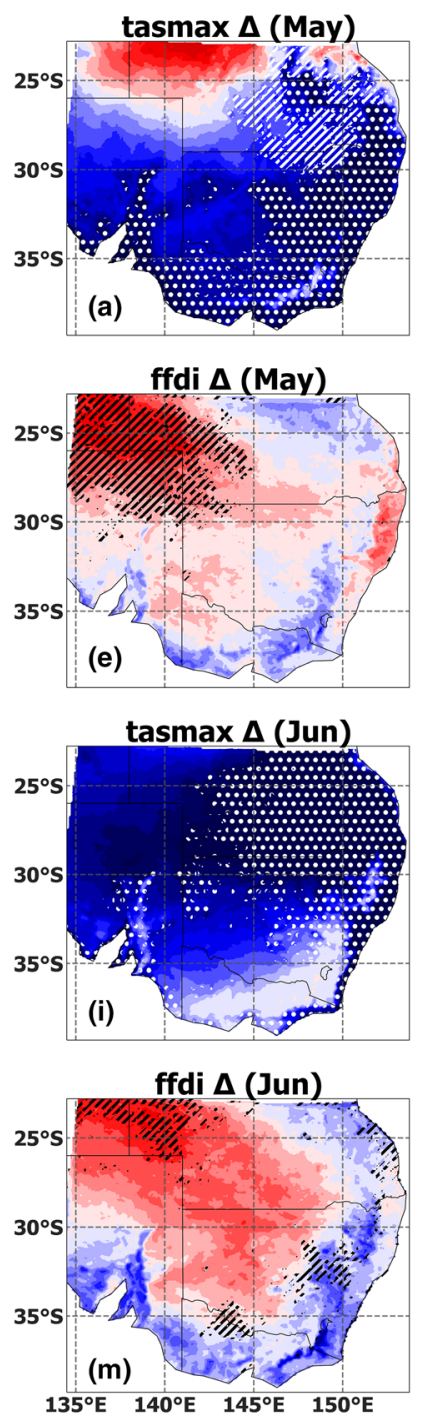

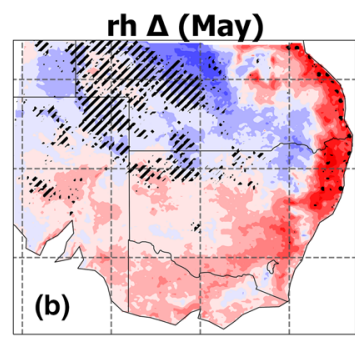

ffdi 3-day $\Delta$ (May)
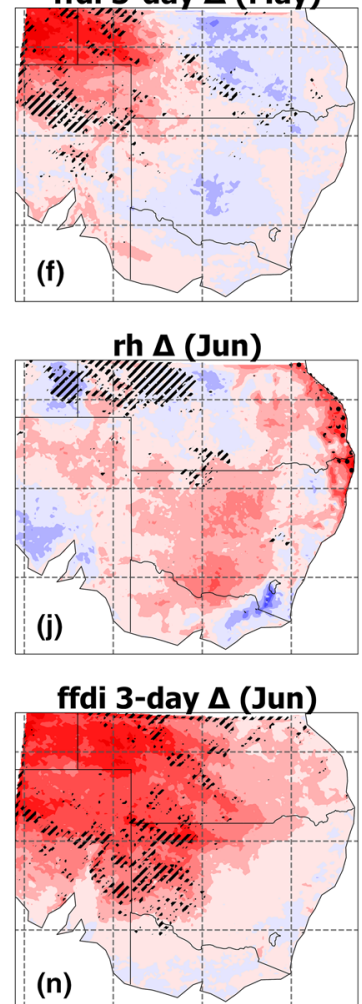

$140^{\circ} \mathrm{E} 145^{\circ}$ (150\%

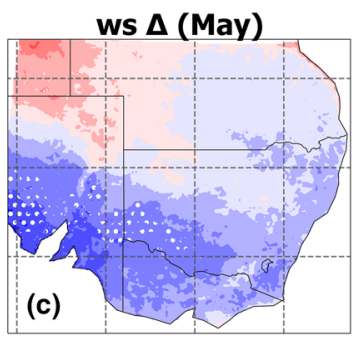

fm $\Delta$ (May)
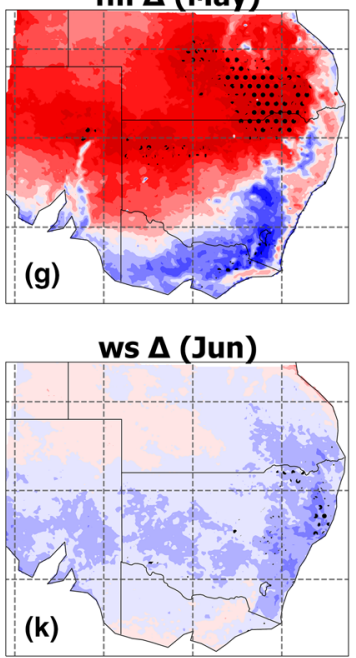

fm $\Delta$ (Jun)

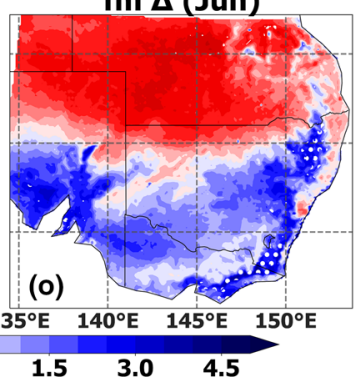

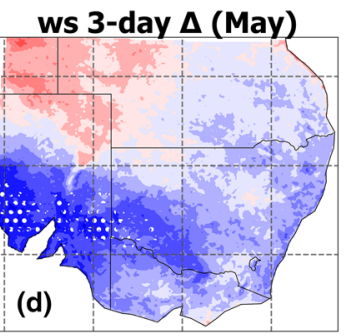

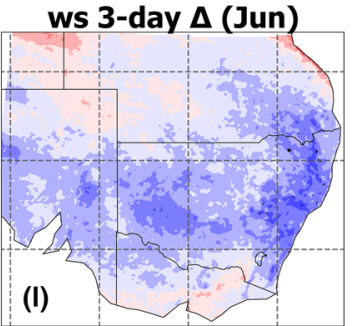

Change in $\mu$ no. days variables within obs. thresholds for conducting burns in May and June, 2060-79 minus 1990-09

Figure 3. (a-o) Change in the mean number of days per month that each variable is within thresholds for conducting prescribed burns in May and June 2060-2079 versus 1990-2009. Stippling as per Figure 2. tasmax = maximum temperature; rh = relative humidity; ws = wind speed; ffdi = Forest Fire Danger Index; $\mathrm{fm}=$ fuel moisture.

(Figure 3a). This is partially attributable to the CCCMA3.1-driven RCMs. These project strong decreases in temperature burn windows across this region, whereas the other nine models project increases (Figure S2). The CCCMA3.1-driven models are substantially warmer in both the present and future periods than the other models (not shown). The ensemble mean maximum temperature climate change signal (Figure 4a) is generally smaller (approximately $+1.5^{\circ} \mathrm{C}$ ) over the southeastern areas showing significant increases in burn days, relative to a projected increase of $+2.25^{\circ} \mathrm{C}$ in the northeastern region showing significant disagreement. There is a significant reduction of $2-3$ days on average when relative humidity is within its weather thresholds over much of the east coast; otherwise, projected changes are smaller over the rest of southeastern Australia (Figure 3b). Much of southeastern Australia is projected to experience increased relative humidity during May, particularly over the eastern coastal region where these changes are significant (Figure 4b). Projections for both wind speed criteria (ws - Figures 3c and 3d) show increases in the mean number of days over most of southeastern Australia. These are mostly small changes, except over the southwest. The climate change signal for wind speed shows reduced magnitudes over large areas of southeastern 

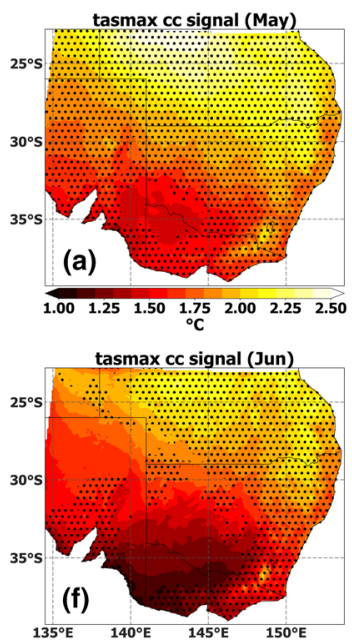
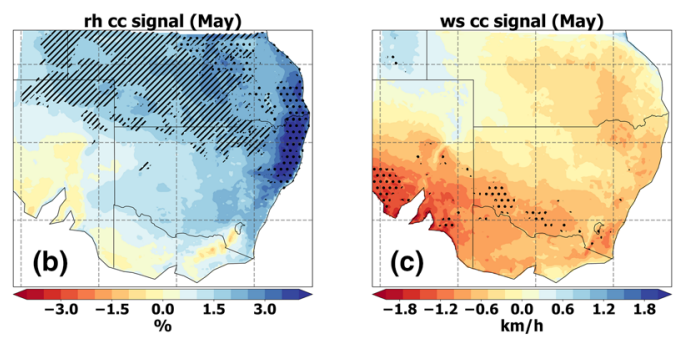

ws cc signal (Jun)
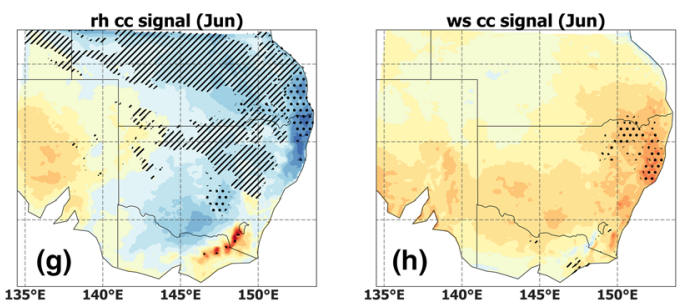
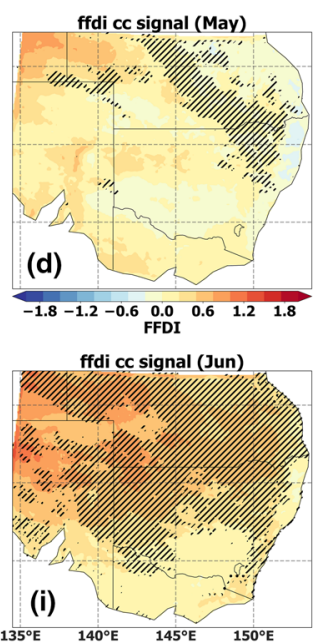

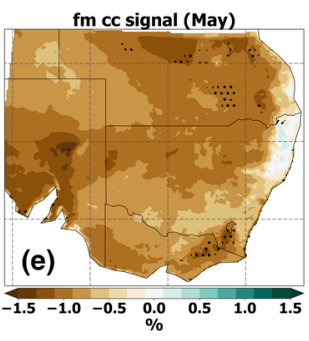

fm cc signal (Jun)

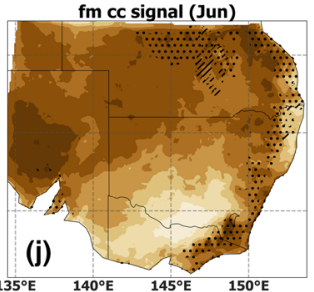

Figure 4. Climate change (cc) signals (far future minus present-day) during May and June for (a and f) maximum temperature (tasmax), (b and g) relative humidity (rh), (c and h) wind speed (ws), (d and i) Forest Fire Danger Index (ffdi), and (e and j) fuel moisture (fm). Color bars apply to corresponding plots for both months. Stippling as per Figure 2 .

Australia, especially over the southwest (Figure 4c). Burn windows for FFDI criteria show a mixture of increases and reductions (Figures $3 e$ and 3f). These changes are fairly small for FFDI 3-day, whereas the "day-of-burn" FFDI criterion shows decreases of $\sim 2$ days over parts of the northeastern coast but increases over the elevated southeastern terrain (Figure 3e). Notably, projected FM shows marked reductions in burn days ( 3 days) over northeastern regions (which are significant in several locations) but conversely increases across a large area of the southeast (Figure $3 \mathrm{~g}$ ). The climate change signal for FM shows widespread reductions, except for a small portion of northeastern NSW (Figure 4e).

During June in 2060-2079 when there are widespread increases in projected burn windows, maximum temperature shows a significant increase of $>4.5$ days when it is within its definitions over much of southeastern Australia (Figure 3i). Although a portion of the southeastern corner is an exception in that it shows minimal increases, no other variable shows significant changes of a similar magnitude and area during June. Relative humidity shows a varying pattern of reductions and increases in its burn window (Figure 3j). Notably, there is a significant decrease in the relative humidity window over the part of the northeastern coastline (Figure 3j) where there is the marked exception to the general pattern of increases to prescribed burn windows during June-October (Figures $2 \mathrm{f}-2 \mathrm{j}$ ). Focusing on this same region, the climate change signal for relative humidity shows significant projected increases exceeding 3\% (Figure 4g). Wind speed generally shows small increases in its burn windows (Figures $3 \mathrm{k}$ and 31 ), associated with widespread decreases in projected wind speeds (Figure 4h). Both FFDI (day-of-burn) and FM record fairly strong increases in their respective burn windows of approximately 1.5-3 days over large coastal and southern regions (Figures 3m and 3o). FFDI climate change signals show slight increases across southeastern Australia (Figure 4i). In contrast, the FM climate change signal decreases significantly over most of the east coast (Figure $4 \mathrm{j}$ ).

\section{Discussion}

Prescribed burns are an important wildfire risk management strategy in Australia and internationally. The imperatives to conduct these burns may increase given that the conditions conducive to wildfire occurrences are becoming more common (AghaKouchak et al., 2014; Jolly et al., 2015; Turco et al., 2018), driven partially by anthropogenic influences including increasing temperatures (Dowdy, 2018). Increased development at rural-urban transitions also increases exposure to the risks associated with wildfires.

Opportunities for conducting prescribed burns across southeastern Australia in 2060-2079 versus 1990-2009 vary spatially and by month. Large portions of southeastern Australia show significant reductions in prescribed burn windows during autumn (March-May), that is, when burns typically occur in the present period, though there are exceptions, such as increased burn days over some regions in May. Conversely, the winter months (June-August) when burns are not commonly conducted show widespread, significant 
increases in burn windows. Moreover, opportunities for conducting burns increase strongly over many regions during September and to a lesser extent in October. Although burns are commonly conducted during September in the present period, they are rarely conducted in October. Clarke et al. (2019) investigated changes to the annual number of burn days and found little evidence for a decrease in burn days. In contrast, this analysis of spatiotemporal changes in the monthly number of burn days shows a more complex pattern of decreases versus increases, dependent upon location and month. However, considering the whole year, much of southeastern Australia is projected to have more days suitable for burning, rather than the opposite scenario, which is consistent with Clarke et al. (2019). It is important that opportunities for conducting prescribed burns remain intact throughout a large portion of the year, given projections that the fire season is likely to occur earlier in future, for example, forward extensions of the season into November (Di Virgilio et al., 2019). Furthermore, the changes described above occur primarily in temperate regions adjacent to the highly populated southeastern urban areas where sclerophyll vegetation communities are prevalent. We recommend caution in interpreting these results for vegetation communities where sclerophyllous plants are not prevalent, that is, principally the central/northwestern semiarid regions. We also note that the McArthur FFDI was built using data from dry sclerophyll forest burning (McArthur, 1967).

Maximum temperature and FM have the largest and most widespread projected changes in the number of days that they are within their respective thresholds for conducting burns. The most geographically widespread changes in burn windows are therefore associated with projected changes in these variables. However, FM projections are partially dependent upon how vegetation is modeled; for example, changes in vegetation productivity with higher $\mathrm{CO}_{2}$ concentrations (Ukkola et al., 2016) could have implications for future vegetation type/condition/land cover changes (Fernández-Martínez et al., 2019). Thus, there is potential uncertainty regarding future FM content and land cover, which may affect some of our findings.

A change in the seasonality of prescribed burn days offers fire agencies continued opportunities to conduct burns in future. In particular, it might be feasible to shift some prescribed burning activity to the winter months and also further into early spring than is the current practice. The increased opportunity for conducting prescribed burns into early spring is important, because there are other operational conditions that would need to be considered under a scenario of increased prescribed burning during winter. A key factor is that inversion layers and increased lower atmospheric stability are common during winter, with a seasonal mean frequency of 50-60\%, compared to $40-50 \%$ in spring (Ji et al., 2019), which increases the chances of lingering fine particulate emissions from fires. Moreover, wintertime near-surface inversions are projected to increase in strength by $20-60 \%$ in $2060-2079$ relative to $1990-2009$, depending upon the region and time of day (Ji et al., 2019). Fire agencies are mindful of the health risks posed to communities by fine particulate emissions from prescribed burns and wildfires, as these are associated with serious health impacts (Dennekamp \& Abramson, 2011; Haikerwal et al., 2016).

In addition to the meteorological and fire weather variables considered here, there are several other factors that are considered by practitioners when planning prescribed burns, such as proximity to infrastructure and human populations, the risks of reignition, and the degree of terrain ruggedness. Moreover, there are other atmospheric and weather phenomena that may warrant consideration when planning prescribed burns, such as the degree of atmospheric instability and dryness and different synoptic weather patterns. More generally, the effectiveness of prescribed burning at mitigating a range of risks is an active area of research (Cirulis et al., 2020; Penman \& Cirulis, 2020), including potential tradeoffs between risks posed by wildfires to human life, economic assets, and other potential consequences such as damage to biodiversity (Penman et al., 2011). It should be noted that prescribed burning is less effective under extreme fire weather conditions (Price \& Bradstock, 2012) and that even under ideal conditions a residual risk remains after its application (Gill et al., 2013).

\section{Conclusions}

Prescribed burning is extensive in Australia and could become more prevalent in a warming climate with increased fire risks, a potentiality that could apply to fire-prone regions globally. This study yielded three main findings: (1) there are statistically significant decreases in prescribed burn windows in 2060-2079 versus 1990-2009 across several regions adjacent to populated urban areas during the periods typically used for conducting burns, that is, March-May; conversely, there are significant increases in burn windows in 
June-August, which is when burns have rarely occurred historically, and in early spring (September and October). That is, the projections indicate a change in the seasonality of prescribed burn days, with a shift toward winter, and not a decline in the annual number of burn days; (2) projected changes in maximum temperature and FM show the largest and most spatially widespread decreases (or increases) in the number of days that are within thresholds for conducting burns; and (3) the locations in southeast Australia where these changes are projected to occur are identified for each month. The weather definition used here assumes each variable is equally important in contributing to suitable prescribed burning weather conditions. The widespread projected changes to the availability of suitable temperature and FM conditions could help inform fire management adaptation to climate change, raising questions about the role and relative importance of these two variables in conducting safe prescribed burning. An important outcome from this study is the demonstration of the spatiotemporal nature of future changes to prescribed burn windows across a large fire-prone region. The increased burn windows in the winter and early spring can provide continued opportunities for prescribed burning in southeastern Australia. These results are strongly relevant to decision makers involved with wildfire prevention, as well as regional risk mitigation. Other fire-prone regions globally may show similarly complex spatiotemporal variations in future opportunities for prescribed burning.

\section{Data Availability Statement}

Climate projection data are available from the AdaptNSW repository: https://climatechange.environment. nsw.gov.au/Climate-projections-for-NSW/Download-datasets.

\section{References}

\section{Acknowledgments}

This project is supported through funding from the Earth Systems and Climate Change Hub of the Australian Government's National Environmental Science Programme and the NSW government Department of Planning Industry and Environment. Logistical support was provided by the Climate Change Research Centre at the University of New South Wales and by the National Computing Infrastructure National Facility at Australian National University. We thank two anonymous reviewers for providing feedback on the manuscript. H. C. thanks the New South Wales Government's Department of Planning Industry and Environment for providing funds to support this research via the Bushfire Risk Management Research Hub. The authors declare that they have no conflict of interest.
Abatzoglou, J. T., Williams, A. P., \& Barbero, R. (2019). Global emergence of anthropogenic climate change in fire weather indices. Geophysical Research Letters, 46, 326-336. https://doi.org/10.1029/2018GL080959

AghaKouchak, A., Cheng, L. Y., Mazdiyasni, O., \& Farahmand, A. (2014). Global warming and changes in risk of concurrent climate extremes: Insights from the 2014 California drought. Geophysical Research Letters, 41, 8847-8852. https://doi.org/10.1002/2014GL062308

Ansell, J., Evans, J., Rangers, A., Rangers, A. S., Rangers, D., Rangers, J., et al. (2020). Contemporary aboriginal savanna burning projects in Arnhem Land: A regional description and analysis of the fire management aspirations of traditional owners. International Journal of Wildland Fire, 29(5), 371-385. https://doi.org/10.1071/WF18152

Bao, J. W., Sherwood, S. C., Alexander, L. V., \& Evans, J. P. (2017). Future increases in extreme precipitation exceed observed scaling rates. Nature Climate Change, 7(2), 128-132. https://doi.org/10.1038/nclimate3201

Bradstock, R. A. (2010). A biogeographic model of fire regimes in Australia: Current and future implications. Global Ecology and Biogeography, 19(2), 145-158. https://doi.org/10.1111/j.1466-8238.2009.00512.x

Bradstock, R. A., Tozer, M. G., \& Keith, D. A. (1997). Effects of high frequency fire on floristic composition and abundance in a fire-prone heathland near Sydney. Australian Journal of Botany, 45(4), 641-655. https://doi.org/10.1071/BT96083

Cirulis, B., Clarke, H., Boer, M., Penman, T., Price, O., \& Bradstock, R. (2020). Quantification of inter-regional differences in risk mitigation from prescribed burning across multiple management values. International Journal of Wildland Fire, 29(5), 414-426. https://doi.org/ 10.1071/WF18135

Clarke, H., \& Evans, J. P. (2019). Exploring the future change space for fire weather in southeast Australia. Theoretical and Applied Climatology, 136(1-2), 513-527. https://doi.org/10.1007/s00704-018-2507-4

Clarke, H., Tran, B., Boer, M., Price, O., Kenny, B., \& Bradstock, R. (2019). Climate change effects on the frequency, seasonality and interannual variability of suitable prescribed burning weather conditions in south-eastern Australia. Agricultural and Forest Meteorology, 271, 148-157. https://doi.org/10.1016/j.agrformet.2019.03.005

Collins, M., Knutti, R., Arblaster, J., Dufresne, J. L., Fichefet, T., Friedlingstein, P., \& Zickfeld, K. (2014). Long-term climate change: Projections, commitments and irreversibility. Cambridge, UK: Cambridge University Press.

Cortes-Hernandez, V. E., Zheng, F. F., Evans, J., Lambert, M., Sharma, A., \& Westra, S. (2016). Evaluating regional climate models for simulating sub-daily rainfall extremes. Climate Dynamics, 47(5-6), 1613-1628. https://doi.org/10.1007/s00382-015-2923-4

de Dios, V. R., Fellows, A. W., Nolan, R. H., Boer, M. M., Bradstock, R. A., Domingo, F., \& Goulden, M. L. (2015). A semi-mechanistic model for predicting the moisture content of fine litter. Agricultural and Forest Meteorology, 203, 64-73. https://doi.org/10.1016/j. agrformet.2015.01.002

Dennekamp, M., \& Abramson, M. J. (2011). The effects of bushfire smoke on respiratory health. Respirology, 16(2), 198-209. https://doi. org/10.1111/j.1440-1843.2010.01868.x

Di Luca, A., Argueso, D., Evans, J. P., de Elia, R., \& Laprise, R. (2016). Quantifying the overall added value of dynamical downscaling and the contribution from different spatial scales. Journal of Geophysical Research: Atmospheres, 121, 1575-1590. https://doi.org/10.1002/ 2015JD024009

Di Virgilio, G., Evans, J. P., Blake, S. A. P., Armstrong, M., Dowd, A. J., Sharples, J., \& McRae, R. (2019). Climate change increases the potential for extreme wildfires. Geophysical Research Letters, 46, 8517-8526. https://doi.org/10.1029/2019GL083699

Di Virgilio, G., Hart, M. A., \& Jiang, N. B. (2018). Meteorological controls on atmospheric particulate pollution during hazard reduction burns. Atmospheric Chemistry and Physics, 18(9), 6585-6599. https://doi.org/10.5194/acp-18-6585-2018

Dowdy, A. J. (2018). Climatological variability of fire weather in Australia. Journal of Applied Meteorology and Climatology, 57(2), 221-234. https://doi.org/10.1175/JAMC-D-17-0167.1

Dowdy, A. J., Ye, H., Pepler, A., Thatcher, M., Osbrough, S. L., Evans, J. P., et al. (2019). Future changes in extreme weather and pyroconvection risk factors for Australian wildfires. Scientific Reports, 9(1), 10,073. https://doi.org/10.1038/s41598-019-46362-x 
Ell, K. (2020). Moody's analytics research, weekly market outlook. Retrieved from https://www.moodysanalytics.com/-/media/article/ 2020/weekly-market-outlook-overvalued-equities-increase-corporate-credits-downside-risk.pdf (Accessed 12-02-2020)

Evans, J. P., Ekström, M., \& Ji, F. (2012). Evaluating the performance of a WRF physics ensemble over south-east Australia. Climate Dynamics, 39(6), 1241-1258. https://doi.org/10.1007/s00382-011-1244-5

Evans, J. P., Ji, F., Lee, C., Smith, P., Argüeso, D., \& Fita, L. (2014). Design of a regional climate modelling projection ensemble experiment NARCliM. Geoscientific Model Development, 7(2), 621-629. https://doi.org/10.5194/gmd-7-621-2014

Fernandes, P. M., \& Botelho, H. S. (2003). A review of prescribed burning effectiveness in fire hazard reduction. International Journal of Wildland Fire, 12(2), 117-128. https://doi.org/10.1071/WF02042

Fernández-Martínez, M., Sardans, J., Chevallier, F., Ciais, P., Obersteiner, M., Vicca, S., et al. (2019). Global trends in carbon sinks and their relationships with $\mathrm{CO}_{2}$ and temperature. Nature Climate Change, 9(1), 73-79. https://doi.org/10.1038/s41558-018-0367-7

Finkele, K., Mills, G. A., Beard, G., \& Jones, D. A. (2006). National gridded drought factors and comparison of two soil moisture deficit formulations used in prediction of Forest Fire Danger Index in Australia. Australian Meteorological Magazine, 55(3), $183-197$.

Fita, L., Evans, J. P., Argueso, D., King, A., \& Liu, Y. (2017). Evaluation of the regional climate response in Australia to large-scale climate modes in the historical NARCliM simulations. Climate Dynamics, 49(7-8), 2815-2829. https://doi.org/10.1007/s00382-016-3484-x

Flannigan, M., Cantin, A. S., de Groot, W. J., Wotton, M., Newbery, A., \& Gowman, L. M. (2013). Global wildland fire season severity in the 21st century. Forest Ecology and Management, 294, 54-61. https://doi.org/10.1016/j.foreco.2012.10.022

Gill, A. M., Stephens, S. L., \& Cary, G. J. (2013). The worldwide "wildfire” problem. Ecological Applications, 23(2), 438-454. https://doi.org/ $10.1890 / 10-2213.1$

Haikerwal, A., Akram, M., Sim, M. R., Meyer, M., Abramson, M. J., \& Dennekamp, M. (2016). Fine particulate matter (PM2.5) exposure during a prolonged wildfire period and emergency department visits for asthma. Respirology, 21(1), 88-94. https://doi.org/10.1111/ resp. 12613

Ji, F., Ekström, M., Evans, J. P., \& Teng, J. (2014). Evaluating rainfall patterns using physics scheme ensembles from a regional atmospheric model. Theoretical and Applied Climatology, 115(1-2), 297-304. https://doi.org/10.1007/s00704-013-0904-2

Ji, F., Evans, J. P., Di Luca, A., Jiang, N. B., Olson, R., Fita, L., et al. (2019). Projected change in characteristics of near surface temperature inversions for Southeast Australia. Climate Dynamics, 52(3-4), 1487-1503. https://doi.org/10.1007/s00382-018-4214-3

Jolly, W. M., Cochrane, M. A., Freeborn, P. H., Holden, Z. A., Brown, T. J., Williamson, G. J., \& Bowman, D. (2015). Climate-induced variations in global wildfire danger from 1979 to 2013. Nature Communications, 6(1), 7537. https://doi.org/10.1038/ncomms8537

Knorr, W., Arneth, A., \& Jiang, L. (2016). Demographic controls of future global fire risk. Nature Climate Change, 6(8), 781-785. https://doi. $\operatorname{org} / 10.1038 /$ nclimate2999

Krofcheck, D. J., Hurteau, M. D., Scheller, R. M., \& Loudermilk, E. L. (2018). Prioritizing forest fuels treatments based on the probability of high-severity fire restores adaptive capacity in Sierran forests. Global Change Biology, 24(2), 729-737. https://doi.org/10.1111/gcb.13913 McArthur, A. G. (1967). Fire behaviour in eucalypt forests. Canberra, Commonwealth of Australia: Forestry and Timber Bureau.

Mitchell, R. J., Liu, Y. Q., O'Brien, J. J., Elliott, K. J., Starr, G., Miniat, C. F., \& Hiers, J. K. (2014). Future climate and fire interactions in the southeastern region of the United States. Forest Ecology and Management, 327, 316-326. https://doi.org/10.1016/j.foreco.2013.12.003

Moritz, M. A., Batllori, E., Bradstock, R. A., Gill, A. M., Handmer, J., Hessburg, P. F., et al. (2014). Learning to coexist with wildfire. Nature, 515(7525), 58-66. https://doi.org/10.1038/nature13946

Nakićenović, N., Alcamo, J., Davis, G., de Vries, B., Fenhann, J., Gaffin, S., \& Dadi, Z. (2000). IPCC Special Report on Emissions Scenarios (SRES). Cambridge, UK: Cambridge University Press.

Noble, I. R., Bary, G. A. V., \& Gill, A. M. (1980). McArthur fire-danger meters expressed as equations. Australian Journal of Ecology, 5(2), 201-203. https://doi.org/10.1111/j.1442-9993.1980.tb01243.x

Nolan, R. H., de Dios, V. R., Boer, M. M., Caccamo, G., Goulden, M. L., \& Bradstock, R. A. (2016). Predicting dead fine fuel moisture at regional scales using vapour pressure deficit from MODIS and gridded weather data. Remote Sensing of Environment, 174, 100-108. https://doi.org/10.1016/j.rse.2015.12.010

NSW Rural Fire Service. (2016). Historical prescribed burns, 2004-2016. https://www.rfs.nsw.gov.au/resources/

Office of Environment and Heritage. (2019). Fire management manual 2018-2019: Policy and procedures for fire management, version 1.0. Sydney, NSW, Australia.

Penman, T. D., Christie, F. J., Andersen, A. N., Bradstock, R. A., Cary, G. J., Henderson, M. K., et al. (2011). Prescribed burning: How can it work to conserve the things we value? International Journal of Wildland Fire, 20(6), 721-733. https://doi.org/10.1071/WF09131

Penman, T. D., \& Cirulis, B. A. (2020). Cost effectiveness of fire management strategies in southern Australia. International Journal of Wildland Fire, 29(5), 427-439. https://doi.org/10.1071/WF18128

Penman, T. D., Kavanagh, R. P., Binns, D. L., \& Melick, D. R. (2007). Patchiness of prescribed burns in dry sclerophyll eucalypt forests in south-eastern Australia. Forest Ecology and Management, 252(1-3), 24-32. https://doi.org/10.1016/j.foreco.2007.06.004

Price, O. F., \& Bradstock, R. A. (2012). The efficacy of fuel treatment in mitigating property loss during wildfires: Insights from analysis of the severity of the catastrophic fires in 2009 in Victoria, Australia. Journal of Environmental Management, 113, 146-157. https://doi.org/ 10.1016/j.jenvman.2012.08.041

Prichard, S. J., Stevens-Rumann, C. S., \& Hessburg, P. F. (2017). Tamm review: Shifting global fire regimes: Lessons from reburns and research needs. Forest Ecology and Management, 396, 217-233. https://doi.org/10.1016/j.foreco.2017.03.035

Skamarock, W. C., Klemp, J. B., Dudhia, J., Gill, D. O., Barker, D. M., Wang, W., \& Powers, J. G. (2008). A description of the advanced research WRF version 3, NCAR Tech Note NCAR/TN-475+STR. Boulder, CO: NCAR.

Tarancon, A. A., Fule, P. Z., Shive, K. L., Sieg, C. H., Meador, A. S., \& Strom, B. (2014). Simulating post-wildfire forest trajectories under alternative climate and management scenarios. Ecological Applications, 24(7), 1626-1637. https://doi.org/10.1890/13-1787.1

Teague, B., McLeod, R., \& Pascoe, S. (2010). 2009 Victorian Bushfires Royal Commission final report. Parliament of Victoria.

Tebaldi, C., Arblaster, J. M., \& Knutti, R. (2011). Mapping model agreement on future climate projections. Geophysical Research Letters, 38, L23701. https://doi.org/10.1029/2011GL049863

Tozer, M. G., Simpson, C. C., Jansens, I. B., \& Keith, D. A. (2017). Biogeography of Australia's dry sclerophyll forests: Drought, nutrients and fire. Cambridge, UK: Cambridge University Press.

Turco, M., Rosa-Canovas, J. J., Bedia, J., Jerez, S., Montavez, J. P., Llasat, M. C., \& Provenzale, A. (2018). Exacerbated fires in Mediterranean Europe due to anthropogenic warming projected with non-stationary climate-fire models. Nature Communications, 9, 9. https://doi.org/ 10.1038/s41467-018-06358-z

Ukkola, A. M., Prentice, I. C., Keenan, T. F., van Dijk, A. I. J. M., Viney, N. R., Myneni, R. B., \& Bi, J. (2016). Reduced streamflow in water-stressed climates consistent with $\mathrm{CO}_{2}$ effects on vegetation. Nature Climate Change, 6(1), 75-78. https://doi.org/10.1038/ nclimate2831 
Westerling, A. L. (2016). Increasing western US forest wildfire activity: Sensitivity to changes in the timing of spring. Philosophical Transactions of the Royal Society, B: Biological Sciences, 371(1696). https://doi.org/10.1098/rstb.2015.0178

Williamson, G. J., Bowman, D., Price, O. F., Henderson, S. B., \& Johnston, F. H. (2016). A transdisciplinary approach to understanding the health effects of wildfire and prescribed fire smoke regimes. Environmental Research Letters, 11(12), 11.

Ximenes, F., Stephens, M., Brown, M., Law, B., Mylek, M., Schirmer, J., et al. (2017). Mechanical fuel load reduction in Australia: A potential tool for bushfire mitigation. Australian Forestry, 80(2), 88-98. https://doi.org/10.1080/00049158.2017.1311200 